\title{
Dilution Kinetics of Chemicals Used for Estimation of Water Content of Body Compartments in Perinatal Medicine
}

\author{
YVES W. BRANS, DONNA S. ANDREW, ELISABETH B. DUTTON, CONNIE A. SCHWARTZ, \\ AND K. D. CAREY \\ From the Neonatal Research Laboratories, Departments of Pediatrics and Obstetrics and Gynecology, Wayne \\ State University School of Medicine, Detroit, Michigan [Y.W.B., D.S.A., C.A.S.]; the Perinatal Research \\ Laboratory, Department of Pediatrics and Obstetrics and Gynecology, The University of Texas Health Science \\ Center, San Antonio, Texas [Y.W.B., D.S.A., and E.B.D.]; and the Department of Physiology and Medicine, \\ Southwest Foundation of Biomedical Research, San Antonio, Texas [Y.W.B., K.D.C.J
}

\begin{abstract}
Dilution kinetics of markers commonly used for estimation of body water content and distribution in perinatal medicine ( $p$-aminohippurate, inulin, antipyrine, $\mathrm{H}_{2}{ }^{18} \mathrm{O}$, bromide, and T1824) were studied in pregnant and neonatal baboons. Amniotic fluid concentrations of $p$-aminohippurate and inulin decreased exponentially after intraamniotic injection of these markers; from 2-24 h after injection, concentrations decreased linearly on semilogarithmic plot $(r=0.96-1.00)$. Plasma concentrations of antipyrine decreased exponentially during the first $60 \mathrm{~min}$ after intravenous injection, then linearly from 1-5 h $(r=$ $0.92-0.90$ ). Plasma concentrations of ${ }^{18} \mathrm{O}$ decreased linearly from 1-6 $\mathrm{h}$ after injection in three or four cases $(r=$ $0.94-0.99)$. Plasma concentrations of bromide decreased during the first $2 \mathrm{~h}$ after injection, then stabilized for at least $3 \mathrm{~h}$. Plasma concentrations of T1824 decreased linearly from 10-60 min after intravenous injection $(r=0.97-$ 1.00). Then the decline became exponential until $5 \mathrm{~h}$. These data allow us to make specific recommendations regarding the optimal time and method of amniotic fluid and blood sampling during body water studies. (Pediatr Res 25:377382,1989 )
\end{abstract}

\section{Abbreviation}

PAH, $p$-aminohippurate

Numerous studies of perinatal physiology, metabolism, nutrition, and pathologic conditions require estimation of the fluid content of various body compartments. As direct volumetric determinations are not possible in vivo, less direct methods must be relied upon to obtain an acceptable estimate. The most commonly used techniques involve a principle developed by Fick. Fick's principle states that the fluid content (V) of a given space may be calculated following the administration of a dye or chemical into that space if the exact amount (Q) of substance injected and its concentration (C) in the fluid of the space are

Reccived August 15, 1988; accepted November 22, 1988

Supported in part by Biomedical Research Grants RR05654 and RR05384 from NIH. by Grant R-328 of the United Cerebral Palsy Research and Educational Foundation. New York. NY, by a grant from the James R. Dougherty, Jr., Foundation, Beeville, TX, by a Research Stimulation Grant from Wayne State University, Detroit. MI, by a grant from Hutzel Hospital, Detroit, MI, and by a grant from the Southwest Foundation Forum, San Antonio, TX.

Address Yves W. Brans, M.D., c/o Hutzel Hospital. Department of Pediatrics, 4707 Saint Antoine Boulevard. Detroit, MI 48201. known, or $\mathrm{V}=\mathrm{Q} / \mathrm{C}$. The dye or chemical must have five main properties: It must 1 ) be harmless to the organism; 2) be easily measurable; 3 ) diffuse evenly and within a predictable period of time throughout its vol of distribution; 4) have no effect on fluxes of fluids across membranes; and 5 ) neither be metabolized nor leave the space for which the vol is being measured for the duration of the study. This last requirement is seldom met. If, however, the decrease in dye concentration with time follows a straight line, extrapolation of that line to time 0 ( $y$-intercept or $\mathrm{C}_{0}$ ) still allows a vol determination to be made, or $\mathrm{V}=\mathrm{Q} / \mathrm{C}_{0}$. In that case, the rate at which the substance escapes from its vol of distribution, be it by metabolism or excretion, may be also calculated (slope of the concentration versus time line).

In cases where all four criteria are met, the marker diffuses as soon as it is administered to reach an even concentration throughout its vol of distribution. In cases where the fourth criterion is not met, two phenomena occur simultaneously as soon as the marker is administered. First, the marker diffuses to reach an even concentration throughout its vol of distribution; second it is being cleared from its assigned space. To interpret the data correctly, it is important to determine at what point in time equilibration is complete and the behavior of the marker concentration thereafter, i.e. the kinetics of the marker. Yet kinetic data have often been disregarded or remained buried in the investigators' laboratory data books and are scarce in the relevant literature. Also, in human perinatal medicine, there are ethical and practical limitations on the number and vol of body fluid samples that may be obtained. In this report, we have made use of the baboon (Papio cynocephalus), whose fetoplacentouterine unit and neonatal physiology and metabolism are very similar to those of Homo sapiens, to determine the kinetics of six markers: PAH (amniotic fluid vol), inulin (amniotic fluid vol), antipyrine (total body water), $\mathrm{H}_{2}{ }^{18} \mathrm{O}$ (total body water), bromide (extracellular water) and T-1824 (plasma vol). From these kinetics, precise recommendations may be made regarding optimal time and method of amniotic fluid or blood sampling.

\section{MATERIALS AND METHODS}

$P A H$ and inulin dilution. The kinetics of PAH and inulin dilution in amniotic fluid were studied in three pregnant baboons (Papio cynocephalus) at 176-178 $\mathrm{d}$ of gestation (term $=180$ days). On the day of the study, each female was anesthetized with $10 \mathrm{mg} / \mathrm{kg}$ of ketamine injected intramuscularly, followed by a mixture of nitrous oxide and halothane for maintenance. Positions of the fetus and placenta were located by ultrasonography with a Toshiba model SAL-20A real-time scanner (Toshiba 
America, Wayne, $\mathrm{NJ}$ ) equipped with a $3.5 \mathrm{MHz}$ linear array transducer. A $60-\mathrm{cm}$ long 16-gauge catheter was inserted into the amniotic cavity. After removal of a $5-\mathrm{mL}$ sample of amniotic fluid, $5 \mathrm{~mL}$ of a sterile solution containing $5 \mathrm{~g} / \mathrm{dL}$ of PAH and $10 \mathrm{~mL}$ of a sterile solution containing $10 \mathrm{~g} / \mathrm{dL}$ of inulin were injected successively through the catheter, followed by $2 \mathrm{~mL}$ of $0.9 \mathrm{~g} / \mathrm{dL}$ sodium chloride as flush. Amniotic fluid samples (1 $\mathrm{mL}$ ) were obtained through the catheter every $10 \mathrm{~min}$ for $4 \mathrm{~h}$ after injection. At $4 \mathrm{~h}$, a blood sample was obtained by femoral venipuncture. After these $4 \mathrm{~h}$, the animal was returned to the cage and allowed to wake up. The animals were again lightly anesthetized with $10 \mathrm{mg} / \mathrm{kg}$ of ketamine for repeat amniocenteses 8 and $24 \mathrm{~h}$ after injection of the markers.

Percutaneous amniocenteses, performed with a 5-cm long 20gauge cannula, were repeated under brief ketamine anesthesia 8 and $24 \mathrm{~h}$ after injection of the markers. All three baboons delivered spontaneously within $3 \mathrm{~d}$ of the study, but they were not in labor at the time of the study. A blood sample was obtained from the neonate by femoral venipuncture.

Amniotic fluid samples were centrifuged for $1 \mathrm{~min}$ at 13500 $\mathrm{rpm}$ in a microcentrifuge, and the supernatants were stored at $-15^{\circ} \mathrm{C}$ until analysis. Blood samples were likewise centrifuged and the plasma stored. Concentrations of PAH in amniotic fluid and plasma were determined in triplicate by a direct spectrophotometric method (1). Concentrations of inulin were determined in quadruplicate by the colorimetric method of Alving et al. (2). The steps removing fermentable carbohydrates and proteins were omitted from the assays of amniotic fluid.

Antipyrine and T-1824 dilution. The kinetics of antipyrine dilution in total body water and of T-1824 dilution in plasma were studied in three normally grown baboon neonates born at term by spontaneous vaginal delivery. At the time of study, their postnatal ages ranged from 13 to $24 \mathrm{~d}$ and their wt ranged from 796 to $860 \mathrm{~g}$. Under ketamine anesthesia, a catheter was inserted into a femoral vein. After removal of a blood sample, $4 \mathrm{~mL} / \mathrm{kg}$ of a sterile solution containing $0.5 \mathrm{~g} / \mathrm{dL}$ of antipyrine (1-phenyl2,3 dimethylpyrazolone-one, Lemnon Company, Sellersville, PA) and $11.3 \mathrm{mg} / \mathrm{dL}$ of T-1824 or Evans' Blue (Harvey Laboratories, Philadelphia, PA) in $0.9 \mathrm{~g} / \mathrm{dL}$ sodium chloride were injected intravenously through the catheter, followed by $2 \mathrm{~mL}$ of $0.9 \mathrm{~g} / \mathrm{dL}$ sodium chloride as flush. Heparinized blood samples were obtained through the catheter at 10 -min intervals during the first $\mathrm{h}$, at $1 \frac{1}{2}, 2,3,4$, and $5 \mathrm{~h}$ after injection of the marker.

Blood samples were centrifuged at $13500 \mathrm{rpm}$ in a microcentrifuge, and the supernatant was stored at $-15^{\circ} \mathrm{C}$ until analysis. Concentrations of antipyrine in plasma were determined in triplicate using a microadaptation of Mendelsohn and Levin's technique (3). Concentration of T-1824 in plasma were determined in duplicate by a double-wavelength technique (4-6).

$\mathrm{H}_{2}{ }^{18} \mathrm{O}$. The kinetics of $\mathrm{H}_{2}{ }^{18} \mathrm{O}$ dilution in total body water were studied in four baboon neonates born at term by spontaneous vaginal delivery. At the time of study, their postnatal ages ranged from 2 to $6 \mathrm{~d}$ and their wt ranged from 586 to $860 \mathrm{~g}$. Under ketamine anesthesia, a catheter was inserted into a femoral vein. After removal of a blood sample, $0.6 \mathrm{~g} / \mathrm{kg}$ of sterile water containing $11.6 \%$ of its oxygen as ${ }^{18} \mathrm{O}$ (Monsanto Research Corporation, Miamisburg, $\mathrm{OH}$ ) were injected intravenously through the catheter, followed by $2 \mathrm{~mL}$ of $0.9 \mathrm{~g} / \mathrm{dL}$ sodium chloride as flush. Heparinized blood samples were obtained hourly for $6 \mathrm{~h}$ after injection of the marker.

Blood samples were centrifuged at $13500 \mathrm{rpm}$ in a microcentrifuge, and the supernatant was stored at $-15^{\circ} \mathrm{C}$ until analysis. The $\delta^{18} \mathrm{O} / \mathrm{mil}$ was determined by equilibrating a known aliquot of plasma with carbon dioxide (7). The ${ }^{18} \mathrm{O} /{ }^{16} \mathrm{O}$ isotope ratio after equilibration was measured with a Finnegan Delta $E$ gas isotope ratio mass spectrometer by a commercial laboratory (Global Geochemistry Corporation, Canoga Park, CA).

Bromide dilution. The kinetics of bromide dilution in extracellular water were studied in three normally grown baboon neonates born at term by spontaneous vaginal delivery. At the time of study, their wt ranged from 1000 to $1295 \mathrm{~g}$. Under ketamine anesthesia, a catheter was inserted into a femoral vein. After removal of a blood sample, $4 \mathrm{~mL} / \mathrm{kg}$ of a sterile solution containing $3.9 \mathrm{~g} / \mathrm{dL}$ of bromide (sodium salt, Bios Coutelier, Brussels, Belgium) in $0.9 \mathrm{~g} / \mathrm{dL}$ sodium chloride were injected intravenously through the catheter, followed by $2 \mathrm{~mL}$ of $0.9 \mathrm{~g} /$ $\mathrm{dL}$ sodium chloride as flush. Heparinized blood samples were obtained through the catheter hourly for $5 \mathrm{~h}$ after injection of the marker.

Blood samples were centrifuged at $13500 \mathrm{rpm}$ in a microcentrifuge and the supernatant was stored at $-15^{\circ} \mathrm{C}$ until analysis. Concentrations of bromide in plasma were determined in triplicate using a microadaptation of Wolf and Eadie's technique (7).

Statistics. The relation between the concentration of a marker and time was analyzed by means of regression analysis.

\section{RESULTS}

The concentrations of PAH and inulin in amniotic fluid decreased exponentially during the $4 \mathrm{~h}$ after their intraamniotic injection ( $r=0.90-0.99$ for PAH and 0.92-0.95 for inulin) (Fig. 1, upper graphs). The decline in concentration was particularly steep during the first 60 to $90 \mathrm{~min}$, then slowed down for the remainder of the 4-h period. The curves describing this decrease in concentrations remained exponential when the logarithm of the concentration was plotted against time. From 2 to $24 \mathrm{~h}$ after injection, the decrease in concentrations became linear if plotted as the natural logarithm of concentration versus time ( $r=1.00$ for PAH and 0.96 to 0.99 for inulin) (Fig. 1, lower graphs). Whereas PAH could be detected in maternal plasma obtained 4 $\mathrm{h}$ after intraamniotic injection, no inulin could be detected. Neither PAH nor inulin could be detected in neonatal plasma obtained shortly after birth.

The concentration of antipyrine in plasma decreased exponentially during the first $60 \mathrm{~min}$ after its intravenous injection. From 1 to $5 \mathrm{~h}$ after injection, there was a slight linear $(r=0.92-0.98)$ decrease in concentration of the order of 0.15 to $0.22 \mathrm{mg} / \mathrm{dL} / \mathrm{h}$ (Fig. 2).

The concentration of ${ }^{18} \mathrm{O}$ represented by $\delta^{18} \mathrm{O} / \mathrm{mil}$, decreased linearly from 1 to $6 \mathrm{~h}$ after injection of water enriched in ${ }^{18} \mathrm{O}(r$ $=0.94-0.99)$ in three of four baboon neonates. In one neonate, there was no change in $\delta^{18} \mathrm{O}$ over time (Fig. 3).

The concentration of bromide decreased exponentially during the first $2 \mathrm{~h}$ after its intravenous injection (Fig. 4). From 2 to 5 $\mathrm{h}$ after injection, the concentrations remained stable.

The concentration of T-1824 in plasma decreased linearly from 10 to $60 \mathrm{~min}$ after its intravenous injection $(r=0.96-1.00)$, then the decline slowed down to become exponential from 1 to $5 \mathrm{~h}$ postinjection (Fig. 5).

\section{DISCUSSION}

Of the various markers that have been used to estimate the vol of amniotic fluid (8-10), PAH has been the most widely used (11-15). Investigators of human pregnancies have mostly used the method of Charles and Jacoby (13), which involved sampling of amniotic fluid before injection of a known amount of PAH and 20 to $40 \mathrm{~min}$ after injection. Mixing of PAH was said to be complete and the PAH concentration stable by the time the second sample was obtained, although no supportive data were offered. Our data from normal baboon pregnancies raise serious questions about the validity of Charles and Jacoby's method (16). Not only does the concentration of PAH fail to stabilize within 20 to $40 \mathrm{~min}$, this time period is situated on a portion of the concentration versus time curve that shows the sharpest decline. Indeed, as the relationship between concentration and time is exponential, the concentration of PAH never does stabilize. With other markers, it has been shown that mixing time of the marker 

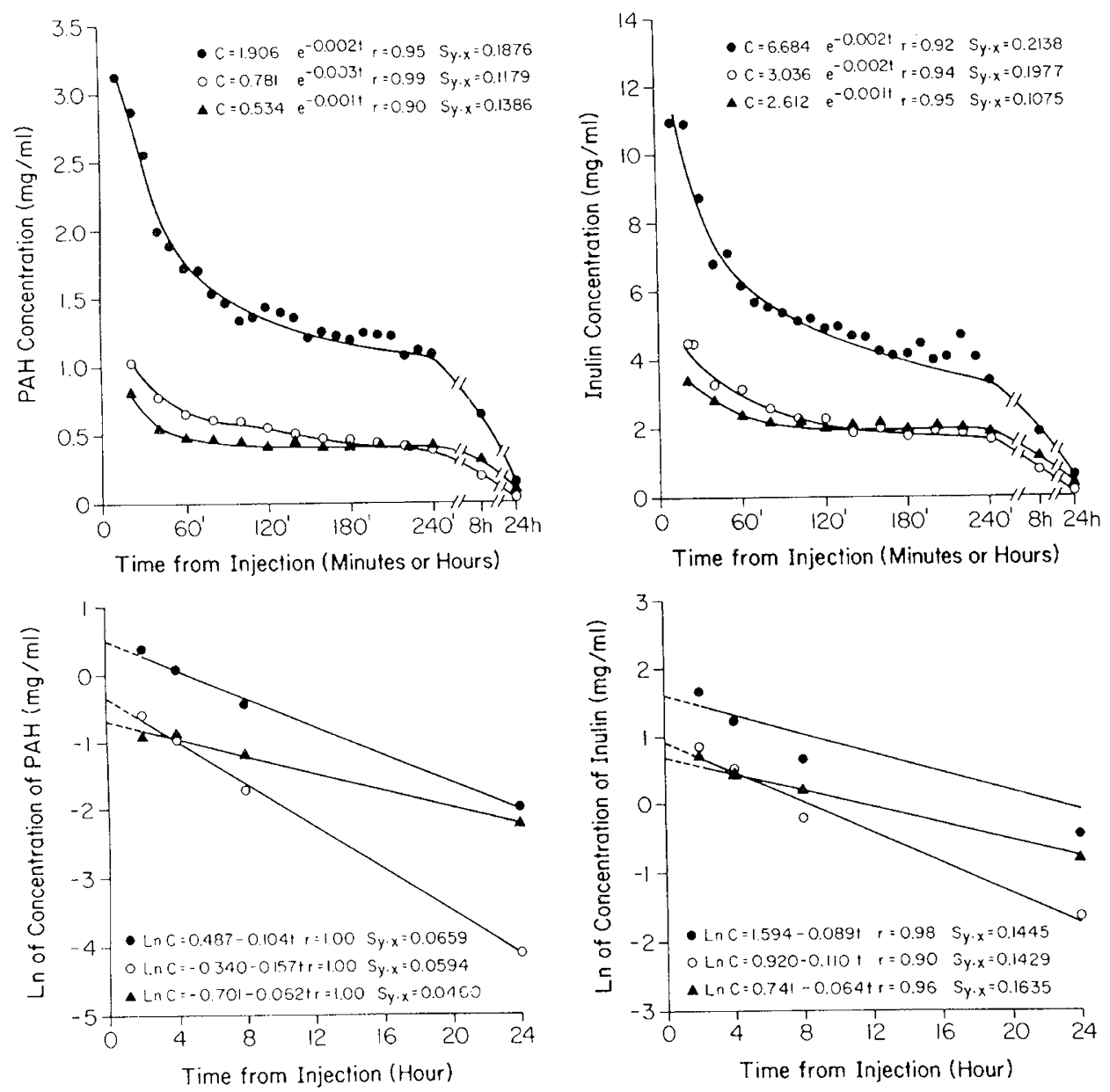

Fig. 1. Concentration vs. time kinetics of $p$-aminohippurate and inulin in amniotic fluid of three baboons at term. Regression equations are calculated from the points shown on each graph. (Modified from Brans YW 1988 Amniotic fluid: volume, composition, ingestion and digestion by the fetus. In Brans YW, Kuehl TJ (eds) Nonhuman Primates in Perinatal Research. John Wiley and Sons, New York, pp 201-216; reproduced by permission.)

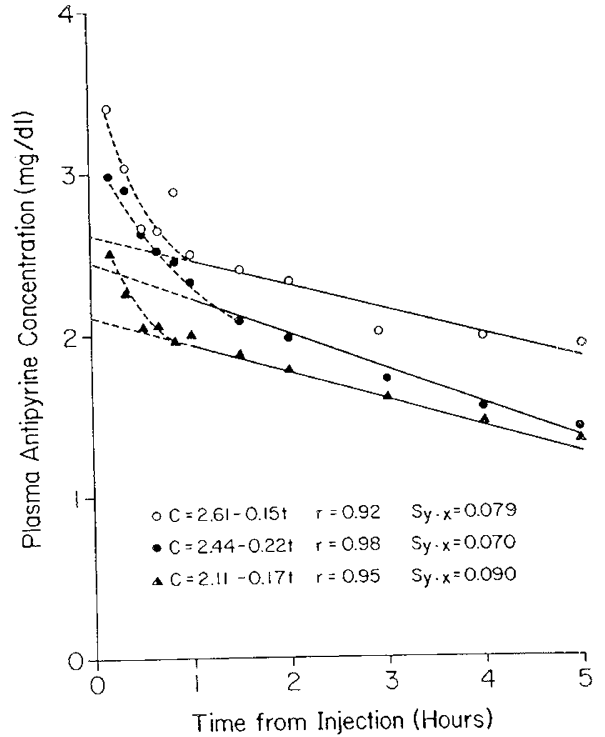

Fig. 2. Concentrations vs. time kinetics of antipyrine in plasma of three baboon neonates.

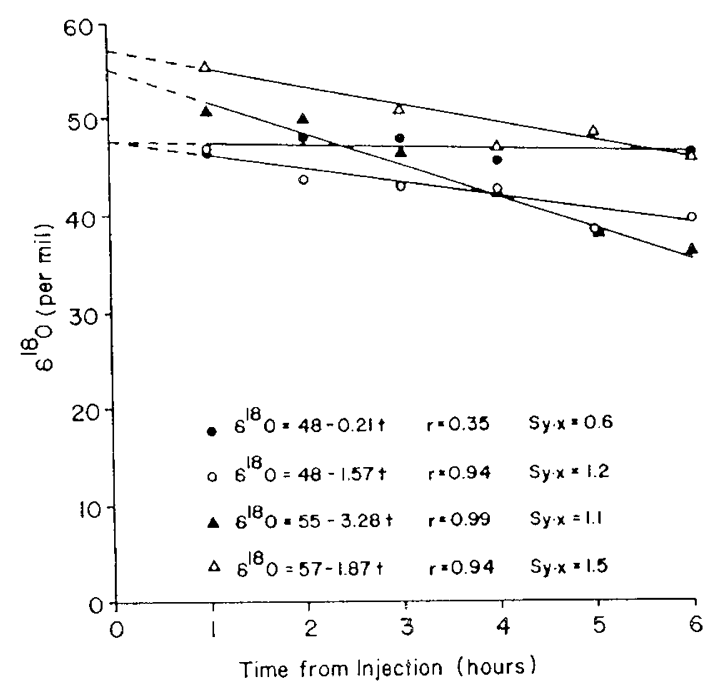

Fig. 3. Concentration $\left(\delta^{18} \mathrm{O} / \mathrm{mil}\right)$ vs. time kinetics of ${ }^{18} \mathrm{O}$ in plasma of four baboon neonates. 


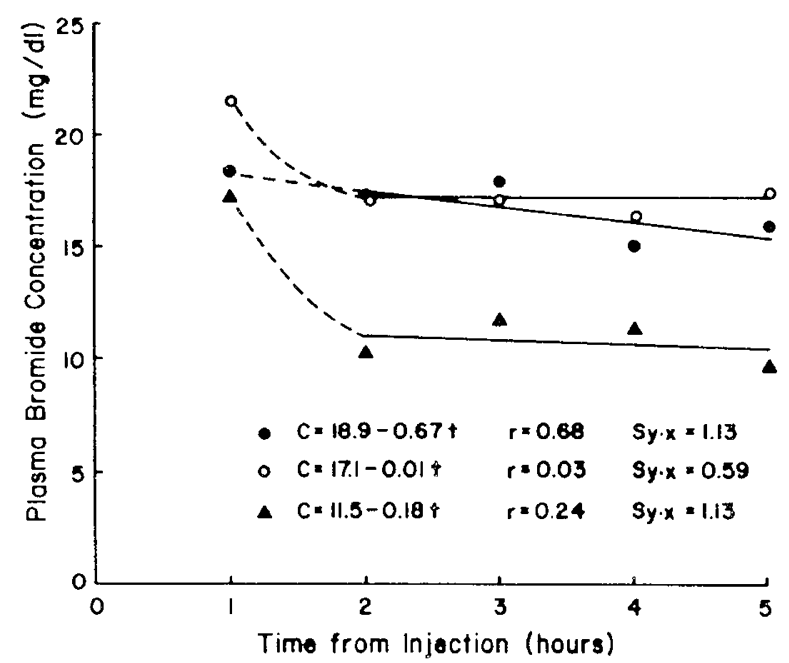

Fig. 4. Concentration $v s$, time kinetics of bromide in plasma of three baboon neonates.

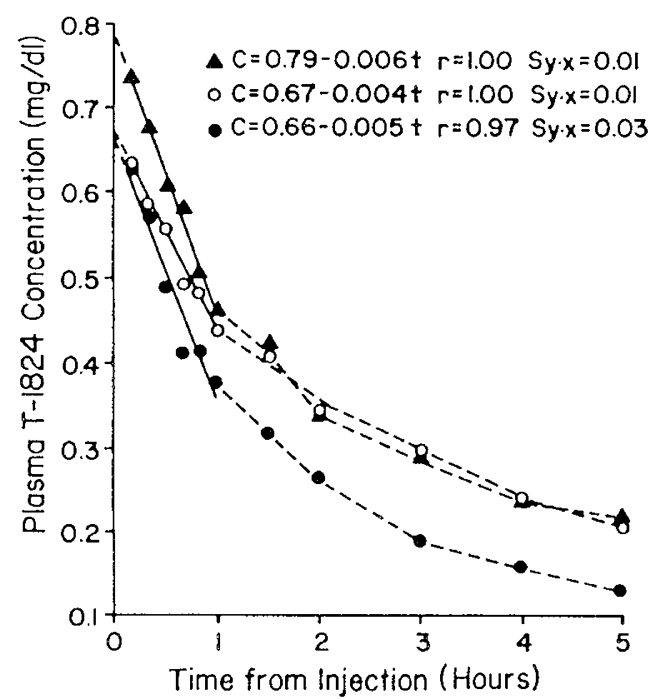

Fig. 5. Concentrations $v$ s. time kinetics of $T-1824$ in plasma of three baboon neonates. The equation reflects the relation between concentration and time (in min) during the first 60 min after injection of T-1824.

varies widely among subjects but is directly proportional to the vol of amniotic fluid $(r=0.93)(10)$. Based on those data, one may predict that in baboons mixing of PAH might be complete in no less than $45 \mathrm{~min}$ after injection, and PAH then begins to be cleared by fetal ingestion and/or through the amniotic membranes. For the larger vol of amniotic fluid in humans, $2 \mathrm{~h}$ after injection would appear to be an adequate mixing time. Our data suggest that at least three postinjection samples of amniotic fluid must be obtained between 2 and $24 \mathrm{~h}$ after injection of a marker to determine the regression line for $\mathrm{PAH}$ clearance and to extrapolate it to time 0 to estimate the vol of amniotic fluid. This admittedly curtails seriously the use of marker techniques in human pregnancies. Recently, real-time ultrasonography has been used to assess amniotic fluid vol qualitatively (17-18). It would be well worth attempting to correlate ultrasonographic estimates with chemical dilution techniques.

Estimates of amniotic fluid vol are difficult to perform in baboons without general anesthesia. The effect of ketamine upon the fetus is not known. Fetal limb and breathing movements persist, and it may be assumed that fetal swallowing is not impaired either (16). Nevertheless, our data must be interpreted cautiously until they are confirmed by results obtained without anesthesia in tethered animals.

Inulin behaves essentially the same way as PAH when injected intraamniotically. It has the advantage of being a larger molecule (mol wt 5000 compared to 194 for PAH), which is unlikely to diffuse out of the amniotic cavity or to be absorbed by the fetal gastrointestinal tract. Indeed no inulin can be found in maternal plasma, whereas PAH can be detected in measurable quantities (16). For this reason, we recommend the use of inulin rather than PAH as a marker of amniotic fluid volume.

While studying the fate of antipyrine in adults, Brodie and Axelrod (19) determined that its concentration in the water of various tissues was nearly identical to that in plasma water, that its excretion was negligible, and that it was metabolized slowly. They suggested that antipyrine might be a useful marker to estimate total body water (20). Its average rate of disappearance of $6 \% / \mathrm{h}$ (range: 1 to $12 \% / \mathrm{h}$ ) made it advisable to obtain serial blood samples and to use the extrapolated time 0 concentration to calculate total body water content. Christian et al. (21) were the first to use antipyrine in neonates, and they obtained serial blood samples at 4.5, 6, 7, and $14 \mathrm{~h}$ after intravenous injection. MacLaurin (22) obtained blood samples 2, 3, and $5 \mathrm{~h}$ after injection. Cassady (23) initially used samples obtained 1,3 , and $5 \mathrm{~h}$ after injection, but later reduced sampling to 1 and $3 \mathrm{~h} \mathrm{(24).}$ None of these investigators provided any data to show that distribution of the marker was complete by the time the first postinjection sample was obtained or that the disappearance rate of antipyrine was linear over the duration of the study. Presumably such data existed but were not published. Murdock et al. (25) showed that low birth wt neonates had increased half-lives for antipyrine and decreased disappearance rates (1.2 \pm [SEM] $0.1 \% / \mathrm{h}$ on the first postnatal $\mathrm{d}, 3.1 \pm 0.3 \% / \mathrm{h}$ on the 4 th $\mathrm{d}$ ) compared to adults. Because, according to our own unpublished data, the decrease in plasma antipyrine was clearly linear between 1 and 5 h post-injection, for convenience we further reduced the timing of blood samples to $1 \mathrm{~h}$ and 1.5 to $2 \mathrm{~h}$ after injection. Our results were identical to those of the other investigators. The data from the present study suggest that distribution of antipyrine in baboon neonates is indeed complete by the end of the 1st postinjection $h$ and that the disappearance rate remains linear for at least $4 \mathrm{~h}$. The exact timing of blood sampling therefore does not matter so long as it occurs between 1 and $5 \mathrm{~h}$ postinjection and that the timing of each sample is known precisely. To improve the accuracy and reproducibility of the technique, it is advisable, whenever possible, to obtain three postinjection blood samples. If circumstances make it difficult to justify multiple blood samples and prolongation of the study, a single postinjection sample may yield adequate data, especially when one is concerned only with comparisons between groups of neonates studied in an identical manner. Our data suggest that using the concentration of antipyrine in plasma obtained $1 \mathrm{~h}$ after its injection rather than the time-0-extrapolated concentration introduces an error of only 4 to $5 \%$, which is within the accuracy of the chemical assay.

It has been stated that the ratio of ${ }^{18} \mathrm{O} /{ }^{16} \mathrm{O}$ in plasma reaches an equilibrium by $4 \mathrm{~h}$ after administration of $\mathrm{H}_{2}{ }^{18} \mathrm{O}$ and maintains that equilibrium for at least $2 \mathrm{~h}$ (26). Our data suggest that this is not true in neonates where the ratio begins to return toward normal within minutes of enrichment with ${ }^{18} \mathrm{O}$. It is therefore necessary to obtain at least two and preferably three blood samples at known times in relation to injection of $\mathrm{H}_{2}{ }^{18} \mathrm{O}$ to calculate the regression line and extrapolate it back to time 0 . Sampling times between 0 and $6 \mathrm{~h}$ after intravenous injection appear to be appropriate. Published results to-date, based on a single determination of $\delta^{18} \mathrm{O}$, probably overestimate the amount of total body weight.

In human adults, bromide is excreted very slowly by the kidneys, at an average rate of $0.3 \% / \mathrm{h}$ during the first $24 \mathrm{~h}$ after administration of an oral dose (27), and the plasma concentra- 
tions stabilize by 2.5 to $3 \mathrm{~h}$ (27). In infants and children, stabilization of plasma concentrations after intravenous administration occurs no later than $2.5 \mathrm{~h}$ and persists for 3 to at least $24 \mathrm{~h} \mathrm{(28).} \mathrm{After} \mathrm{subcutaneous} \mathrm{injection} \mathrm{in} \mathrm{neonates,} \mathrm{a} \mathrm{constant}$ vol of distribution is observed for 3 to $12 \mathrm{~h}$ (29). These data led most investigators to select a single blood sample, obtained $3 \mathrm{~h}$ after administration of bromide, to calculate the bromide space $(23,29-34)$, although there was no evidence that stabilization of plasma bromide concentrations did not occur earlier after intravenous injection. In the past, we chose to use $1 \mathrm{~h}$ as a convenient time of sampling in both human and baboon neonates $(24,35-$ $41)$. The resulting data for group averages were essentially identical to those obtained with the use of a 3-h sample. The data from the current study suggest that distribution of bromide after intravenous injection is not complete by $1 \mathrm{~h}$, but is complete by $2 \mathrm{~h}$ and that the plasma concentrations remain stable for at least the next $3 \mathrm{~h}$. For greater accuracy, blood sampling should occur no earlier than $2 \mathrm{~h}$ after injection.

The determination of plasma vol with $\mathrm{T}-1824$, as originally described in adults, involved a single sampling of blood exactly 10 min after injection of the marker (42), and most investigators have used this simplified technique $(6,24,35-38,40,43-49)$ rather than the most cumbersome method of employing a series of successive samples and extrapolation back to time 0 . In neonates, although the rate of transcapillary escape of T-1824 is considerably greater than in adults -20 to $30 \% / \mathrm{h}(5,35,44,50$, 51) versus $5 \% / \mathrm{h}(42)$-the error introduced by using a single sample is small $(3 \%$ : at $20 \% / \mathrm{h}$ average $\mathrm{T}-1824$ rate of transcapillary escape, $3 \%$ are lost in $10 \mathrm{~min}$ ) and well within the limits of accuracy of the laboratory assay (44). Even in circumstances when excessive loss of intravascular albumin (and T-1824 bound to it) may be suspected, as in erythroblastosis fetalis, the use of serial samples has little effect on the mean plasma vol determinations $(48,51)$. Barr et al. (49) compared the T-1824 concentrations at $10 \mathrm{~min}$ with that at time 0 , obtained by linear retropolation of the disappearance curve, in both hypotensive and normotensive neonates and found no significant differences. Our data from baboons are in agreement with those from other investigators. They indicate that the disappearance curve of $T$ 1824 from plasma is linear during the 1 st $h$ after injection, then becomes exponential. Calculations of plasma vol based on the 10 -min concentration versus retropolation of the disappearance curve introduces an error of at most $5 \%$.

This report does not address the issue of accuracy and validity of in vivo estimates of body water content and distribution, nor does it provide data favoring one marker versus another for any given fluid compartment except amniotic fluid. Validation studies with whole body chemical analyses are needed to resolve these important issues.

\section{REFERENCES}

1. Thompson W, Lappin TRJ, Elder GE 1971 Liquor volume by direct spectrophotometric determination of injected PAH. Br J Obstet Gynaecol 78:341344

2. Alving AS, Rubin J, Miller BF 1939 A direct colorimetric method for the determination of inulin in blood and urine. J Biol Chem 127:609-616

3. Mendelsohn D. Levin NW 1960 A colorimetric micromethod for the estimation of antipyrine in plasma and serum. S Afr J Med Sci 25:13-18

4. Nielsen MH and Nielsen NC 1972 Spectrophotometric determination of Evans blue dye in plasma with individual correction for blank density by a modified Gaeblers method. Scand J Clin Lab Invest 14:605-617

5. Parving HH. Klebe JG, Ingomar CJ 1973 Simultaneous determination of plasma volume of transcapillary escape rate with 131-I-labelled albumin and $\mathrm{T}-1824$ in the newborn. Acta Paediatr Scand 62:248-252

6. Brans YW, Shannon DL, Ramamurthy RS 1981 Neonatal polycythemia. II. Plasma, blood and red cell volume estimates in relation to hematocrit level and quality of intrauterine growth. Pediatrics 68:175-182

7. Cohn M. Urey HC 1938 Oxygen exchange reaction of organic compounds and water. J Am Chem Soc 60:679-687

8. Wolf RL, Eadie GS 1939 Reabsorption of bromide by the kidney. Am J Physiol 163:436-441

9. Dieckmann WJ. Davis ME 1933 The volumetric determination of amniotic fluid with Congo Red. Am J Obstet Gynecol 25:623-627
10. Neslen ED, Hutchison DL, Hallet RL, Plenth AA 1954 Dilution methods for determination of amniotic fluid volume. Obstet Gynecol 3:598-607

11. Rosa P 1951 Etude de la circulation du liquide amniotique humain. Gynecol Obstet 50:463-476

12. Edelberg SC, Kochwa S, Rosenficld RE. Cherry SH 1968 Amniotic fluid PAH clearance test. Am J Obstet Gynecol 102:585-590

13. Charles D, Jacoby HE 1966 Preliminary data on the use of sodium aminohippurate to determine amniotic fluid volumes. Am J Obstet Gynecol 95:266269

14. Charles D, Jacoby HE, Burgess F 1965 Amniotic fluid volumes in the second half of pregnancy. Am J Obstet Gynecol 93:1042-1047

15. Van Otterlo LC, Wladimiroff JW. Wallenburg HCS 1977 Relationship between fetal urine production and amniotic fluid volume in normal pregnancy and in pregnancy complicated by diabetes. Br J Obstet Gynaecol 84:205-209

16. Brans YW, Kuehl TJ, Hayashi RH, Shannon DL, Reyes P 1984 Chemical dilution and clcarance studies to estimate amniotic fluid volume and amniotic fluid ingestion in normal baboon pregnancies. Am J Primatol 6:3140

17. Chamberlain PF, Manning FA, Morrison I, Harman CR, Lange IR 1984 Ultrasound evaluation of amniotic fluid volume. I. The relationship of marginal and decreased amniotic fluid volumes to perinatal outcome. Am J Obstet Gynecol 150:245-249

18. Chamberlain PF, Manning FA, Morrison I, Harman CR, Lange IR 1984 Ultrasound evaluation of amniotic fluid volume: II The relationship of increased amniotic fluid volume to perinatal outcome. Am J Obstet Gynecol $150: 250-254$

19. Brodie BB, Axelrod J 1950 The rate of antipyrine in man. J Pharmacol Exp Ther 98:97-104

20. Soberman R, Brodie BB, Levy BB, Axelrod J, Hollander V, Steele JM 1949 Use of antipyrine in measurement of total body water in man. J Biol Chem 179:31-42

21. Christian JR, Talso PJ, Karazeris MP, Spafford NR, Jackson H, Larson M 1956 Total body water and exchangeable sodium in normal full-term newborn infants. Am J Dis Child 92:325-329

22. MacLaurin JC 1966 Changes in body water distribution during the first two weeks of life. Arch Dis Child 41:286-291

23. Cassady G, Milstead RR 1971 Antipyrine space studies and cell water estimates in infants of low birth weight. Pediatr Res 5:673-682

24. Brans YW, Dweck HS, Harris B, Parr GVS, Bailey PE, Kirklin JW, Cassady G 1981 Effect of open-heart surgery on the body composition of infants and young children. Pediatr Res 15:1024-1028

25. Murdock AI, Thorgeirsson Ss, Rossiger H, Davies DS 1975 Serial measurements of plasma half-lives and urinary excretion of antipyrine in low-birthweight infants. Biol Neonat 27:289-30

26. Trowbridge FL, Graham GG, Wong WW, Mellits Ed, Rabold JD, Lee LS, Cabrera MP, Klein PD 1984 Body water measurements in premature and older infants using $\mathrm{H}_{2}{ }^{18} \mathrm{O}$ isotopic determinations. Pediatr Res 18:524-527

27. Cheek DB 1953 Estimation of the bromide space with a modification of Conway's method. J Appl Physiol 5:639-645

28. Forbes GB, Reid AF, Bondurant J, Etheridge J 1956 Changes in total body chloride during growth. Pediatrics 17:334-340

29. Fink CW, Cheek DB 1960 The corrected bromide space (extracellular volume) in the newborn. Pediatrics 26:397-401

30. Cheek DB 1961 Extracellular volume: its structure and measurement and the influence of age and disease. J Pediatr 58:103-125

31. Clapp WM, Butterfield LJ O'Brien D 1962 Body water compartments in the premature infant with special reference to the effects of the respiratory distress syndrome and of maternal diabetes and toxemia. Pediatrics 29:883889

32. Cassady G 1970 Bromide space studies in infants of low birth weight. Pediatr Res 4:20-30

33. Cheek DB, Wishart J, MacLennan AH, Haslam R 1984 Cell hydration in the normally-grown, the premature and the low weight for gestational age infant. Early Hum Dev 10:75-84

34. Rojas J, Mohan P, Davidson KK 1984 Increased extracellular water volume associated with hyponatremia at birth in premature infants. $J$ Pediatr 105:158-161

35. Thornton CVJ, Shannon DL, Hunter MA, Ramamurthy RS, Brans YW 1983 Body water estimates in neonatal polycythemia. J Pediatr 102:113-117

36. Brans YW, Kuehl TJ, Hayashi RH, Shannon DL, Reyes P 1983 Body water estimates in normally-grown baboon neonates. Am J Primatol 5:69-75

37. Brans YW, Cornish JD, Kuehl TJ, Dutton EB, Andrew DS, Menchaca EM 1986 Effect of extracorporeal membrane oxygenation on body water content and distribution of baboon neonates. Pediatr Res 20:381-384

38. Brans YW, Kuehl TJ, Hayashi RH, Andrew DS 1986 Body water estimates in intrauterine growth retarded versus normally-grown baboon neonates. Biol Neonate 50:231-236

39. Brans YW, Sumners JE, Dweck HS, Bailey PE, Cassady G 1976 Feeding the low birth weight infant: orally or parenterally? II: corrected bromide space in parenterally-supplemented infants. Pediatrics 58:809-815

40. Thornton CJ, Shannon DL, Hunter MA, Brans YW 1982 Dynamic skinfold thickness measurements: a noninvasive estimate of neonatal extracellular water. Pediatr Res 16:989-994

41. Brans YW, Shannon DL, Hunter MA 1983 Maternal diabetes and neonatal macrosomia: III Neonatal body water estimates. Early Hum Dev 8:307-316 
42. Gregersen MI 1944 A practical method for the determination of blood volume with the dye T-1824. J Lab Clin Med 29:1266-1286

43. Nitshe GA Jr, Cohen PP 1947 Simplified determination of blood volume. Am $\mathrm{J}$ Clin Pathol 17:239--243

44. Mollison PL, Veall N, Cutbush M 1950 Red cell and plasma volume in newborn infants. Arch Dis Child 25:242-253

45. Sisson TRC, Lund CJ, Whalen LE, Telek A 1959 The blood volume of infants: I: The full-term infant in the first year of life. J Pediatr 55:163-179

46. Low JA, Kerr ND, Cochon AR 1963 Plasma and blood volume of the normal newborn infant and patterns of adjustment in initial 24 hours of the neonatal period. Am J Obstet Gynecol 86:886-892

47. Cassady G 1966 Plasma volume studies in low birth weight infants. Pediatrics
38:1020-1027

48. Brans YW, Milstead RR, Bailey PE, Cassady G 1974 Blood-volume estimates in Coombs-test-positive infant. N Engl J Med 290:1450-1452

49. Barr PA, Bailey PE, Sumner J, Cassady G 1977 Relation between arterial blood pressure and blood volume and effect of infused albumin in sick preterm infants. Pediatrics 60:282-289

50. Ingomar CJ, Klebe JG, Baekgaard P 1973 The transcapillary escape rate of T1824 in healthy newborn infants: the influence of the placental transfusion. Acta Paediatr Scand 62:617-620

51. Phibbs RH, Johnson P. Tooley WH 1974 Cardiorespiratory status of erythroblastotic newborn infants. II. Blood volume, hematocrit, and serum albumin concentration in relation to hydrops fetalis. Pediatrics 53:13-23

\section{Announcement}

\section{CHILD HEALTHCARE FIELD RESEARCH IN BRAZIL}

Medical professionals, especially nurse and M.D. medical anthropologists, are needed to participate in field research focusing on child healthcare in Brazil.

The University Research Expeditions Program, now in its 13th year, makes it possible for interested members of the public to spend 2 to $3 \mathrm{wk}$ as active members of a University of California research team. No previous experience is necessary for most expeditions.

The expedition teams, which usually include 8 to 10 participants, leave for destinations all over the world throughout the year, although most are concentrated in summer and winter. Participants in all UREP expeditions make a tax-deductible contribution to cover their expenses and help make the research possible.

For a free catalog and applications, contact desk K03, University Research Expeditions Program, University of California, Berkeley, CA 94720. Phone: (415) 642-6586. 